\title{
Magnetic and Electric Studies of a New Cu(II) Perovskite-like Material
}

\author{
Mohga F. Mostafa and Ahmed A. A. Youssef \\ Physics Department, Faculty of Science, University of Cairo, Giza, Egypt \\ Reprint requests to Dr. M.F. M.; E-mail : Mohga40@hotmail.com.
}

Z. Naturforsch. 59a, 35 -46 (2004); received September 20, 2003

Thermal analysis of a lipid-like bilayer of $\left[\left(\mathrm{CH}_{2}\right)_{9}\left(\mathrm{NH}_{3}\right)_{2}\right] \mathrm{CuCl}_{4}$ indicates one minor transition at $303 \mathrm{~K}$ and the following five major ones (with entropies in $\mathrm{J} / \mathrm{K}$-mole):

$$
\begin{aligned}
& \text { Phase } \frac{T_{5}=188 \mathrm{~K}}{\Delta S_{5}=5.43} \text { Phase } \frac{T_{4}=228 \mathrm{~K}}{\Delta S_{4}=1.90} \text { Phase } \frac{T_{3}=288 \mathrm{~K}}{\Delta S_{3}=4.06} \text { Phase } \frac{T_{2}=346 \mathrm{~K}}{\Delta S_{2}=0.36} \text { Phase } \frac{T_{1}=383 \mathrm{~K}}{\Delta S_{1}=3.80} \text { Phase. } \\
& \begin{array}{lllll}
\text { (VI) } & \text { (V) } & \text { (III) } & \text { (II) }
\end{array}
\end{aligned}
$$

The initial magnetic susceptibility at $320 \mathrm{~Hz}$ and a magnetic field of $160 \mathrm{~A} / \mathrm{m}$ in the temperature range $75-290 \mathrm{~K}$ revealed a Curie-Weiss behavior of phase (V) and possible ferromagnetic ordering of phases (VI) and (IV) at low temperatures. The variation of the dielectric permittivity with temperature at $60.0 \mathrm{~Hz}-100 \mathrm{kHz}$ indicates large changes of the dipole moment at the transition temperatures. The conductivity is thermally activated and frequency dependent, following the universal power law: $\sigma(\omega)=\sigma_{\mathrm{dc}}+A(T) \omega^{s(T)}$. Values of $s$ being phase dependent. For phase (I), $T>383 \mathrm{~K}$, band type conduction prevails. Hopping conduction is found in phases(II) and (III). Comparison with other Cuand Cd-containing materials is made. - PACS: 76, 77

Key words: Magnetic Susceptibility; AC Conductivity; Permittivity; Structure Transitions.

\section{Introducion}

The structures, phase transitions and magnetic properties of perovskite-type layer materials have intensively been investigated during the past years [110]. Many studies on the "monoammonium series" $\left[\left(\mathrm{C}_{n} \mathrm{H}_{n+1} \mathrm{NH}_{3}\right)\right]_{2} \mathrm{MX}_{4}, n=1,2,3, \ldots, \mathrm{M}=\mathrm{Mn}, \mathrm{Fe}, \mathrm{Cu}$, $\ldots, \mathrm{X}=\mathrm{Cl}$, have been carried out $[1-3,6,8]$. The structural changes of these materials result from the reorientation of the alkylammonium chains coupled with tilt of the $\mathrm{MX}_{6}$-octaheda occurring in the perovskite layers. Such studies have also been made on the "diammonium series" $\left[\left(\mathrm{CH}_{2}\right)_{n}\left(\mathrm{NH}_{3}\right)_{2}\right] \mathrm{MX}_{4} ; n=2,3, \ldots$, $\mathrm{M}=\mathrm{Mn}, \mathrm{Fe}, \mathrm{Cu}, \ldots, \mathrm{X}=\mathrm{Cl}, \mathrm{Br}[4,5,9-11]$. Recently we have focussed our studies on the electric behavior of the diammonium-series because of its relative stability and the H-bonds in it $[11-15]$. They are interesting in electrochemical devices such as batteries, fuel cells, chemical sensors, electrochromic devices and supercapacitors.

These materials crystallize in a two-dimensional perovskite-like structure, in which the link between adjacent $\mathrm{MX}_{6}$ octahedral planes is performed by the alkylene chains bearing $\left(\mathrm{NH}_{3}\right)$ groups of both ends
$[1-3,16]$. X-ray investigations have shown that materials with an even number of carbon atoms are monoclinic with two formula units per unit cell, whereas an odd number of carbon atoms leads to an orthorhombic room temperature structure with four formula units per unit cell $[1,2]$. Table 1 lists the lattice spacings and transition temperatures of some of these materials with different transition metals and different numbers of carbon atoms.

In our previous studies some members of the diammonium family, where $\mathrm{M}$ was $\mathrm{Fe}, \mathrm{Mn}, \mathrm{Cd}$, and $\mathrm{Cu}$, showed interesting permittivity and conductivity results $[11-15]$. In those studies we used diammmonium ions with even numbers of $C$ atoms $(C=6,10$ and 12). The aim of the present work is to characterize the structural phase transitions and to investigate the electric and magnetic properties of a long chain diammonium compound having an odd number of carbon atoms $(C=9)$. Comparison of the results with the previously studied materials having even numbers of carbon atoms will be carried out. Thus we have prepared the new material $\left[\left(\mathrm{CH}_{2}\right)_{9}\left(\mathrm{NH}_{3}\right)_{2}\right.$ $\mathrm{CuCl}_{4}$ ], which is named $\mathrm{CuC} 9$, and have studied its properties. 


\begin{tabular}{llllllll}
\hline Compound & Cryst. System & $\beta\left(^{\circ}\right)$ & $a(\AA)$ & $b(\AA)$ & $c(\AA)$ & $T_{\mathrm{c}}(\mathrm{K})$ & \\
\hline$\left(\mathrm{CH}_{2}\right)_{2}\left(\mathrm{NH}_{3}\right)_{2} \mathrm{CdCl}_{4}$ & Monoclinic & 92.8 & 8.624 & 7.297 & 7.342 & & {$[1]$} \\
$\left(\mathrm{CH}_{2}\right)_{2}\left(\mathrm{NH}_{3}\right)_{2} \mathrm{MnCl}_{4}$ & monoclinic & 98.86 & 8.609 & 7.13 & 7.192 & & {$[2]$} \\
$\left(\mathrm{CH}_{2}\right)_{2}\left(\mathrm{NH}_{3}\right)_{2} \mathrm{CuCl}_{4}$ & monoclinic & 92.46 & 8.11 & 7.36 & 7.187 & & {$[2]$} \\
$\left(\mathrm{CH}_{2}\right)_{3}\left(\mathrm{NH}_{3}\right)_{2} \mathrm{CdCl}_{4}$ & Orthorhombic & & 7.329 & 7.481 & 9.007 & 374 & {$[4]$} \\
$\left(\mathrm{CH}_{2}\right)_{3}\left(\mathrm{NH}_{3}\right)_{2} \mathrm{MnCl}_{4}$ & orthorhombic & & 7.172 & 7.378 & 9.004 & 305 & {$[5]$} \\
$\left(\mathrm{CH}_{2}\right)_{3}\left(\mathrm{NH}_{3}\right)_{2} \mathrm{CuCl}_{4}$ & orthorhombic & & 7.108 & 7.378 & 18.57 & & {$[1]$} \\
$\left(\mathrm{CH}_{2}\right)_{4}\left(\mathrm{NH}_{3}\right)_{2} \mathrm{MnCl}_{4}$ & Monoclinic & - & & & & 382 & {$[4]$} \\
$\left(\mathrm{CH}_{2}\right)_{4}\left(\mathrm{NH}_{3}\right)_{2} \mathrm{PbCl}_{4}$ & monoclinic & 94.84 & 7.944 & 7.772 & 9.761 & 323 & {$[10]$} \\
$\left(\mathrm{CH}_{2}\right)_{5}\left(\mathrm{NH}_{3}\right)_{2} \mathrm{CdCl}_{4}$ & orthorhombic & - & 21.32 & 7.44 & 24.11 & 338 & {$[4]$} \\
$\left(\mathrm{CH}_{2}\right)_{6}\left(\mathrm{NH}_{3}\right)_{2} \mathrm{CdCl}_{4}$ & monoclinic & 91.24 & 23.935 & 7.306 & 7.587 & & {$[4]$} \\
$\left(\mathrm{CH}_{2}\right)_{10}\left(\mathrm{NH}_{3}\right)_{2} \mathrm{CdCl}_{4}$ & monoclinic & - & & & & & {$[15]$} \\
$\left(\mathrm{CH}_{2}\right)_{12}\left(\mathrm{NH}_{3}\right)_{2} \mathrm{CuCl}_{4}$ & monoclinic & - & & & & & {$[16]$} \\
\hline
\end{tabular}

Table 1. Room temperature crystallographic data of $\left[\left(\mathrm{CH}_{2}\right)_{n}\left(\mathrm{NH}_{3}\right)_{2}\right] \mathrm{MCl}_{4} n=2$, $3,4,5,6,10$, and $12, \mathrm{M}=$ $\mathrm{Cd}, \mathrm{Mn}, \mathrm{Cu}$, and $\mathrm{Pb}$.

$\beta$ is the angle, $a, b$, and $c$ are the lattice parameters, and $T_{\mathrm{c}}$ is the transition temperature.

\section{Experimental}

\subsection{Sample Preparation}

CuC9 was prepared as described in [6,9]. The yellow sample was recrystallized from a mixture of alcohol and ether, and dried under vacuum. The chemical analysis was carried out at the microanalysis unit at the University of Cairo. The material showed the correct chemical formula. The results of the analysis are listed in Table 2.

\subsection{Infrared Spectroscopy}

The IR spectra between $4000 \mathrm{~cm}^{-1}$ and $200 \mathrm{~cm}^{-1}$ were obtained on an FTIR 5000 spectrometer.

\subsection{Thermal Analysis}

Differential scanning calorimetry (DSC) measurements were performed on a Shimadzu (50) differential scanning analyzer with a scanning speed of $5{ }^{\circ} \mathrm{C} / \mathrm{min}$. The data were calibrated with the melting transition of Indium at $157^{\circ} \mathrm{C}$.

\subsection{Susceptibility Measurements}

The differential magnetic susceptibility was measures in the temperature range $78 \mathrm{~K}-300 \mathrm{~K}$, at $320 \mathrm{~Hz}$ and in a magnetic field of $160 \mathrm{~A} / \mathrm{m}$, using a Lakeshore 7000-series AC Susceptometer/Magnetometer.

\subsection{Dielectric Measurements}

The complex dielectric permittivity $\varepsilon^{*}$ in the frequency range $600 \mathrm{~Hz}-100 \mathrm{kHz}$ was measured using a computer controlled lock-In amplifier, Stanford research type SR830. The samples were in the form of pellets, $1 \mathrm{~mm}$ thick and $8 \mathrm{~mm}$ in diameter. The faces
Table 2. Results of chemical analysis for $\left[\left(\mathrm{CH}_{2}\right)_{9}\right.$ $\left.\left(\mathrm{NH}_{3}\right)_{2}\right] \mathrm{CuCl}_{4}$.

\begin{tabular}{lccccc}
\hline Element & $\% \mathrm{C}$ & $\% \mathrm{H}$ & $\% \mathrm{~N}$ & $\% \mathrm{Cl}$ & $\% \mathrm{Cu}$ \\
\hline Wt\% (Calc.) & 29.54 & 5.56 & 7.66 & 17.37 & 38.85 \\
Wt\% (Found) & 30.01 & 6.01 & 7.9 & 17.45 & 36.7 \\
\hline
\end{tabular}

Table 3. Absorption bands and their assignment for $\left[\left(\mathrm{CH}_{2}\right)_{n}\right.$ $\left.\left(\mathrm{NH}_{3}\right)_{2}\right] \mathrm{CuCl}_{4}, n=9$ and $12 \mathrm{~cm}^{-1}$.

\begin{tabular}{ccl}
\hline \multicolumn{2}{l}{ Wave No $\left(\mathrm{cm}^{-1}\right)$ for } & \\
CuC9 & CuC12 & Attributed to \\
\hline 278,249 & 259,235 & Bridging (MX)6; CuCl layer mode \\
394,359 & 338 & C-N Tor \\
727 & 725 & Sr(CH2) \\
1484 & 1400 & CH2 Wagging/(NH3)+/C-H Str. \\
1580 & 1580 & N-H Def. \\
2852 & 2851 & N-H...Cl \\
2922 & 2924 & C-H Str. \\
3125 & 3129 & C-H Str./(NH3)+ (vs) \\
3425 & 3426 & C-H Str. \\
\hline
\end{tabular}

were coated with silver paste to ensure good electrical contact. Different samples were used with the same results. Measurements were carried out while heating and cooling.

\section{Results and Discussion}

\subsection{Infrared}

Table 3 lists the most characteristic absorption peaks and their assignment. These are bands associated with the $\mathrm{CH}_{2}$ rocking motions, which are usually strong, and the much weaker $\mathrm{CH}_{2}$ wagging, which is not always observable. The bands at $765 \mathrm{~cm}^{-1}$ and $730 \mathrm{~cm}^{-1}$ are assigned to the $\mathrm{CH}_{2}$ rocking fundamental mode $\delta_{r}\left(\mathrm{CH}_{2}\right)$ [17]. The $\mathrm{CH}_{2}$ wagging modes are found at $1150-1400 \mathrm{~cm}^{-1}$ for the crystalline nparaffins. These modes are mixed with the $\left(\mathrm{NH}_{3}\right)^{+}$ modes. The coupling with $\left(\mathrm{NH}_{3}\right)^{+}$may be the reason for the strong enhancement of the intensity of the 
$\mathrm{CH}_{2}$ wagging modes compared to the corresponding ones in the case of $n$-alkanes. For CuC9, $\delta_{r}\left(\mathrm{CH}_{2}\right)$ is found at $727 \mathrm{~cm}^{-1}$, and wagging coupled with $\left(\mathrm{NH}_{3}\right)^{+}$ is found at $1484 \mathrm{~cm}^{-1}$. This band could also have contributions from $\delta\left(\mathrm{CH}_{2}\right)$ deformation. The band at $1496 \mathrm{~cm}^{-1}$ probably belongs to the $\left(\mathrm{NH}_{3}\right)$ symmetric deformation mode. The strong band at $1580 \mathrm{~cm}^{-1}$ is assigned to $\delta_{\mathrm{as}}\left(\mathrm{NH}_{3}\right)$. The bands at $394 \mathrm{~cm}^{-1}$ and $359 \mathrm{~cm}^{-1}$ are attributed to the $\mathrm{C}-\mathrm{N}$ torsional mode, while the strong bands at $278 \mathrm{~cm}^{-1}$ and $249 \mathrm{~cm}^{-1}$ confirm the formation of the layered structure. Upon comparing the ir of this material with the corresponding one containing 12 carbon atoms, one sees that the $\mathrm{Cu}-\mathrm{Cl}$ and $\mathrm{C}-\mathrm{N}$ torsional bands are shifted to lower frequency with increase of the number of carbon atoms. The other vibrational or rotational modes are essentially the same, considering the accuracy of the spectrometer. The ir results and the results of the chemical analysis confirm the formation of the desired material.

\subsection{Differential Scanning Calorimetry}

A DSC thermograph for a powdered $\mathrm{CuC} 9$ sample obtained during heating is shown in Figure 1. The endothermic peak at $425 \mathrm{~K}$ is associated with blackening of the material, indicative of its dissociation. Table 4 lists the transition temperatures, the enthalpies $\Delta H$ and the corresponding entropies $\Delta S$. Transition temperatures are found at $T_{1}=(383 \pm 2) \mathrm{K}, T_{2}=(346 \pm 4) \mathrm{K}$, and $T_{3}=(288 \pm 2) \mathrm{K}$, followed by a minor peak with onset temperature at $\sim 303 \mathrm{~K}$. Major transitions preceded or followed by minor ones have been observed in phospholipids and are attributed to "chain melting" [18]. At the chain melting rapid diffusion of one or more gauche bonds up and down the hydrocarbon chain takes place, where the chain increases in length [4,5]. Kind et al. [4] reported two phase transition of $\left[\left(\mathrm{CH}_{2}\right)_{10}\left(\mathrm{NH}_{3}\right)_{2}\right] \mathrm{CdCl}_{4}$, a minor one at $308 \mathrm{~K}$ preceding the major transition at $312 \mathrm{~K}$, with a total enthalpy of $8.9 \mathrm{cal} / \mathrm{mole}$. They associated the minor transition with dynamic two fold rotational disorder of the chain, and the major transition was attributed to the "melting" of the chain. DSC and X-ray investigation of some long chain "monoammonium" series have also indicated the first order nature of these transition [19]. The temperature and order of the transition depends on the length of the organic chain and not on the metal ion. The nature of the second transition depends on whether it occurs at a higher or lower temperature than
Table 4. The temperatures, enthalpies, and entropies of the transitions of $\left[\left(\mathrm{CH}_{2}\right)_{n}\left(\mathrm{NH}_{3}\right)_{2}\right] \mathrm{CuCl}_{4}$.

\begin{tabular}{lccccc}
\hline$T(\mathrm{~K})$ & $T 5$ & $T 4$ & $T 3$ & $T 2$ & $T 1$ \\
\hline$T$ & $188 \pm 2$ & $228 \pm 4$ & $288 \pm 2$ & $346 \pm 4$ & $383 \pm 2$ \\
$\Delta H(\mathrm{~kJ} / \mathrm{mole})$ & 1.02 & 0.44 & 1.17 & 0.122 & 1.46 \\
$\Delta S(\mathrm{~J} / \mathrm{K}-\mathrm{mole})$ & 5.43 & 1.9 & 4.06 & 0.36 & 3.8 \\
\hline
\end{tabular}

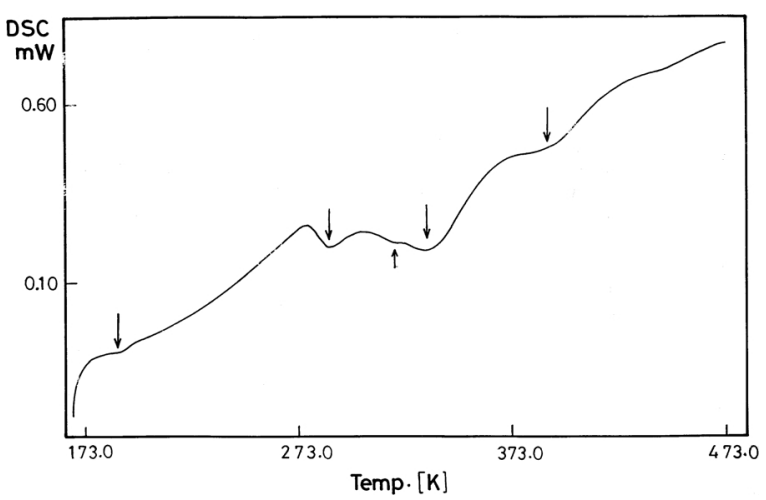

Fig. 1. Differential scanning thermograph (DSC) in the range $179 \mathrm{~K}-433 \mathrm{~K}$ for $\mathrm{CuC} 9$.

the chain melting transition, but in either case corresponds to the onset of a two-fold disorder of the chain orientation. X-ray investigations by Kind et al. [4] have indicated that the chain undergoes rapid motion, and the interlayer spacing increases as a result of this transition. The rapid motion at the minor transition is due to flipping of the chain between two equivalent positions. Thus, for the presently studied $\mathrm{CuC} 9$ material one can attribute the major transition at $288 \mathrm{~K}$ and the minor transition at $303 \mathrm{~K}$ to the chain melting and the flipping of the chain between equivalent positions. The large entropy found for the $T_{1}$-transition indicates an order-disorder transition. At $\mathrm{T}_{2}$ a $\lambda$-like peak, having a low temperature tail, suggests a first order transition. At $T<273 \mathrm{~K}$, transition peaks at $T_{4}=(228 \pm 2) \mathrm{K}$ and $T_{5}=(188 \pm 3) \mathrm{K}$ were observed. The transitions $T_{4}$ and $T_{5}$ have a $\lambda$-like shape of large enthalpies, which may indicate first order crystalline phase changes. Such low temperature crystalline transitions have been reported for materials of the "monoammonium series" [20] and "diammonium series". These transitions are ascribed to changes in the crystal symmetry related to the freezing $\mathrm{C}-\mathrm{N}$ oscillation $[2,16,21]$.

\subsection{Magnetic Susceptibility Results}

Figure 2.a shows the corrected molar magnetic susceptibility $\left(\chi_{\mathrm{M}}\right)$ and its reciprocal $\left(1 / \chi_{\mathrm{M}}\right)$ in an ac field 


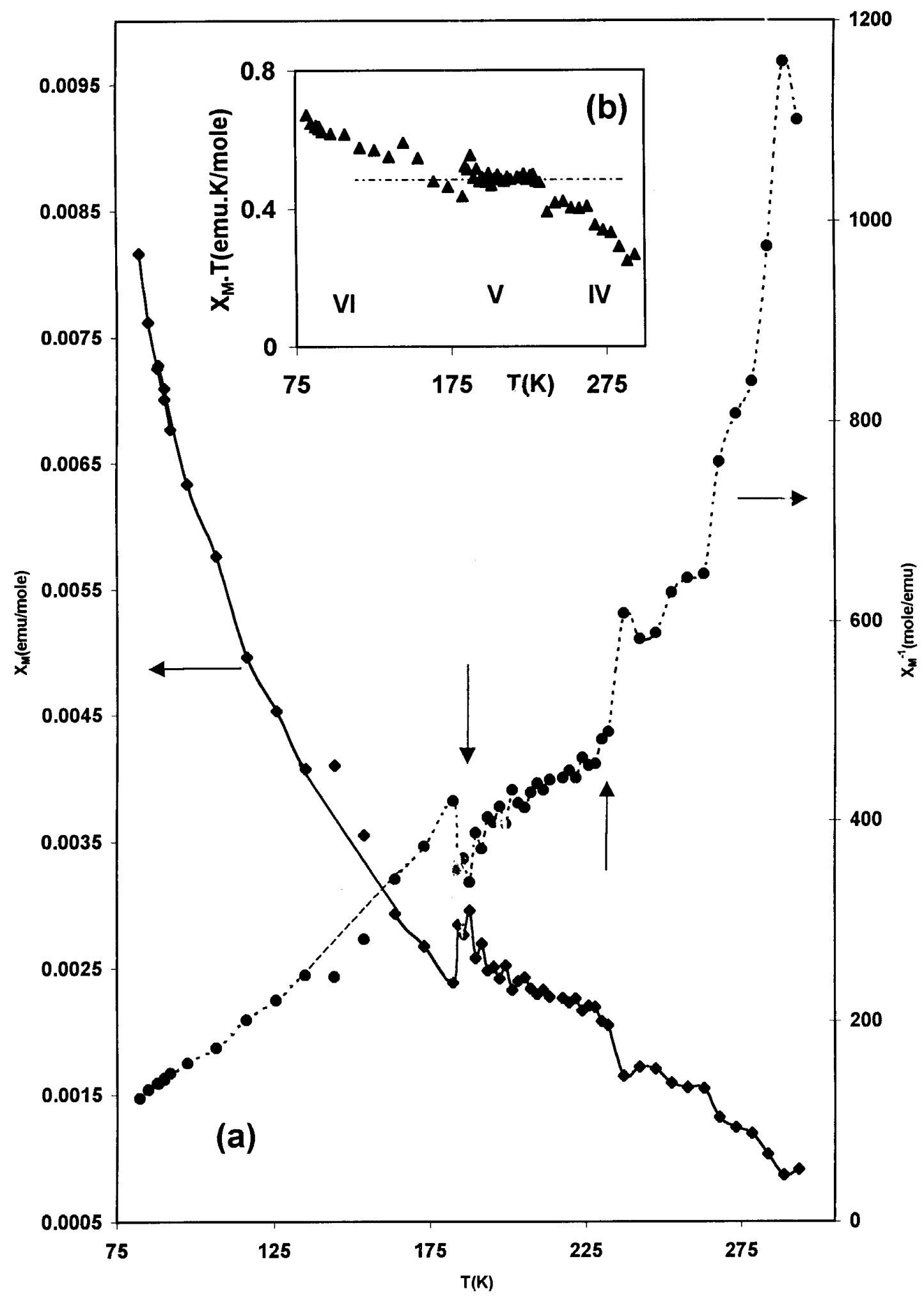

Fig. 2. (a) The corrected molar magnetic susceptibility $\chi_{\mathrm{M}}$ and its reciprocal as function of $T$ in the range $78-290 \mathrm{~K}$ for CuC9. (b) $\left(\chi_{\mathrm{M}} T\right)$ as function of $T$ in the range $78-290 \mathrm{~K}$ for $\mathrm{CuC} 9$. 
of $160 \mathrm{~A} / \mathrm{m}$ and $320 \mathrm{~Hz}$ in frequency. The two transitions at $\sim 188 \mathrm{~K}$ and $\sim 228 \mathrm{~K}$ are clearly reflected in the variations of $1 / \chi_{\mathrm{M}}$ with temperature, as designated by the arrows. Figure 2.b shows $\chi_{\mathrm{M}} T$ as function of temperature. In the temperature regime, $228-188 \mathrm{~K}$, phase (V), the Curie-Weiss law is followed with an effective magnetic moment of $1.91 \mathrm{BM}$, which is typical for $\mathrm{Cu}^{2+}$ in a distorted octahedral arrangement. A jump in the $\chi_{\mathrm{M}} T$ values is quite clearly seen at the designated transition temperatures. Increase in $\chi_{M} T$ with decreasing temperature, reflecting positive deviation from Curie-type behavior, is noted for the phases VI, $T<188 \mathrm{~K}$, and IV $288>T>228 \mathrm{~K}$, suggesting a ferromagnetic interaction of these phases at low temperatures. It is clear that the obtained susceptibility supports the structural phase transitions obtained from the DSC results. It also indicates the possibility of shortrange order interaction for phase VI. Magnetic susceptibility measurements at low temperatures as function of frequency and magnetic field are underway.

\section{Dielectric Results}

\subsection{Permittivity}

The temperature dependence of the real part $\varepsilon^{\prime}$ of the complex dielectric permittivity at selected frequencies, in the temperature range $280-400 \mathrm{~K}$, is shown in Figure 3.a. The data are obtained while heating up the sample. A close look at the data around $288 \mathrm{~K}$ shows a sudden drop in permittivity followed by a frequency and temperature independent permittivity as seen by the insert (Figure 3.b). A drop in permittivity on heating through the transition temperature has been connected with the cooperative melting of the $\mathrm{CH}_{2}$ group [2,14]. At $320 \mathrm{~K}$ a large dispersion starts to take place, reaching a plateau at $\sim 346 \mathrm{~K}$. This behavior is typical for a rotational type transition, where rotational motion of the alkylene chains results in a large dipole moment fluctuation $[6,14,15]$. Another anomalous change, noted at $383 \mathrm{~K}$, as depicted by an arrow, agrees also with the observed anomalies in the DSC results. This is most likely associated with rearrangement of dipole moments resulting from the order disorder transition. Figure 3.c shows the imaginary part of permittivity $\left(\varepsilon^{\prime \prime}\right)$ for the same sample. The graph shows the same general features as that of Fig. 3.a, yet the changes are more prominent. The inserts ( $3 \mathrm{~d}$ and $3 \mathrm{e}$ ) show the changes in the permittivity around $346 \mathrm{~K}$ and $288 \mathrm{~K}$, respectively.

\subsection{Dielectric Modulus}

The observed frequency dispersion of the permittivity arises from the electrode polarization, which is determined by technical factors, e.g. sample dimension and/or nature of the electrode surface. Macedo et al. [22] have introduced the electrical modulus $M^{*}=1 / \varepsilon^{*}$ to overcome the effect of electrode polarization, $M^{*}=M^{\prime}+i M^{\prime \prime}=\left\{1 /\left(\varepsilon^{\prime}\left(1+\tan \delta^{2}\right)\right\}+\right.$ $\left\{i \tan d / \varepsilon^{\prime \prime}\left(1+\tan \delta^{2}\right)\right\}$. The imaginary part $M^{\prime \prime}$ of the complex electric modulus does not include the contribution from the electrode effect. It is to be noted that both $M^{*}(v)$ and $\sigma^{*}(v)$ are derived from the same experimental data (i.e., real and imaginary components of the sample impedance). However, the shape of the modulus is sensitive to $\varepsilon^{\prime}(\propto)$, the high frequency limiting permittivity that results from near instantaneous electronic and atomic polarization, which is not directly related to hopping of the mobile ions. The frequency dependence, at different temperatures, of the real $M^{\prime}$ and imaginary $M^{\prime \prime}$ parts of the complex dielectric modulus as function of frequency $(\ln \omega)$ are shown in Figs. 4a and 4b. The plots show features of ionic conductors, namely an $S$ shaped dispersion in $M^{\prime}$ and a peak in $M^{\prime \prime}$. Relaxation peaks were found for the phases I, $380 \mathrm{~K}<T<400 \mathrm{~K}$, and II, $346 \mathrm{~K}<T<$ $380 \mathrm{~K}$. The relaxation peak moves through the temperature "window" or frequency "window" as the temperature and/or frequency changes. The relaxation behavior of phase II can be analyzed assuming a simple exponential activation law:

$$
f=f_{0} \exp \left(-E_{\mathrm{a}} / k T\right),
$$

which yields $E_{\mathrm{a}}=0.86 \mathrm{eV}$ and $\tau_{0}=3.45 \cdot 10^{-16} \mathrm{sec}$, as shown in Figure 4.c. No analysis was carried out for phase I because of the limited number of data points.

\subsection{Conductivity Results}

\section{Temperature Dependence}

Figure 5.a shows the Arrhenius plot of the conductivity as a function of temperature at selected frequencies. A frequency dependent, temperature independent behavior prevails for $T<320 \mathrm{~K}$, with very small activation energies of $0.008 \mathrm{eV}$, indicating extrinsic type conduction. Chain melting transition is reflected by scattered data at $3.57 \mathrm{~K}^{-1}<1000 / T<3.35 \mathrm{~K}^{-1}$. At higher temperatures, a thermally activated behavior with activation energies dependent on frequency is 

$\times 1510$
* 4010
- $\varepsilon 010$
$+10000$
- 15000
- 20000
$\rightarrow 40000$
* $100000 \mathrm{~Hz}$
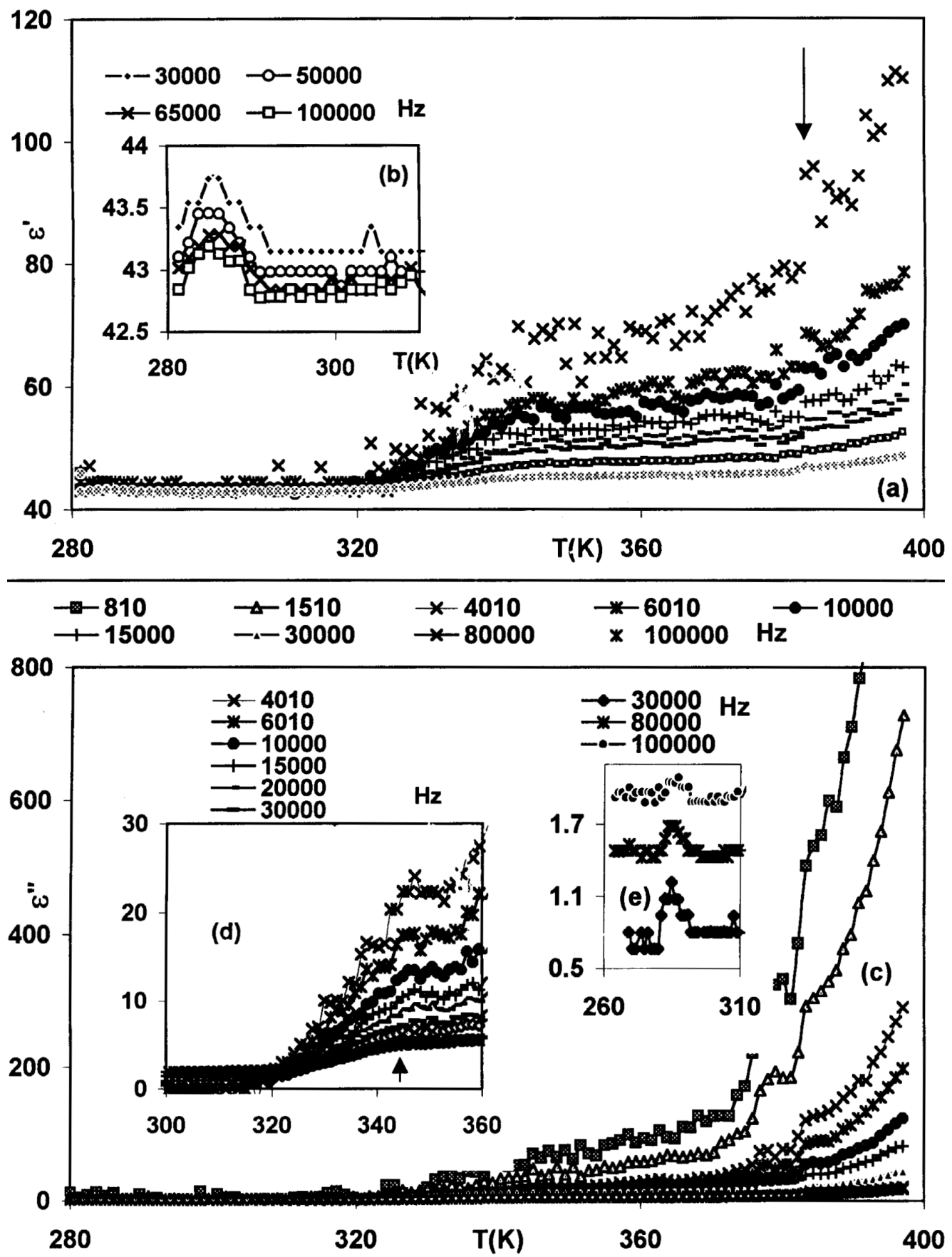

Fig. 3. The complex dielectric permittivity $\left(\varepsilon^{\prime}+i \varepsilon^{n}\right)$ as a function of $T$ for $\mathrm{CuC} 9$ at different frequencies, obtained while heating up the virgin sample: (a) Real part $\varepsilon^{\prime}$ at 280-400 K. (b) Real part $\varepsilon^{\prime}$ at $280-310 \mathrm{~K}$. (c) Imaginary part $\varepsilon^{\prime \prime}$ at $260-$ $400 \mathrm{~K}$. (d) Imaginary part $\varepsilon^{\prime \prime}$ at $300-360 \mathrm{~K}$. (e) Imaginary part $\varepsilon^{\prime \prime}$ at $260-310 \mathrm{~K}$. 

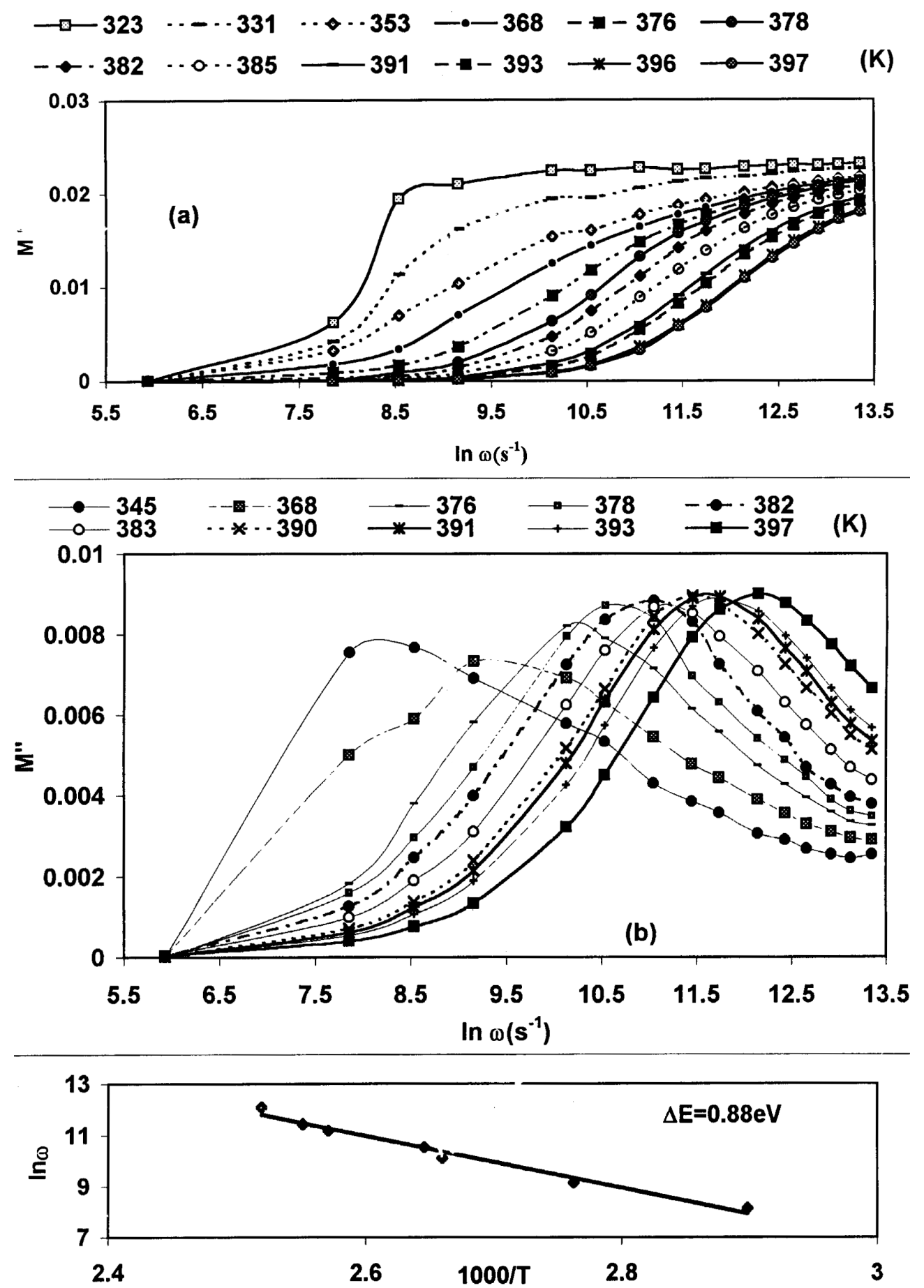

Fig. 4. (a) Real part $M^{\prime}$ of the dielectric modulus as function of the frequency while heating the sample CuC9. (b) Imaginary part $M^{\prime \prime}$ of the dielectric modulus as function of the frequency while heating the sample CuC9. (c) Semi-logarithmic plot of the frequency $(\omega)$ as function of $1000 / T$ for phase II. 


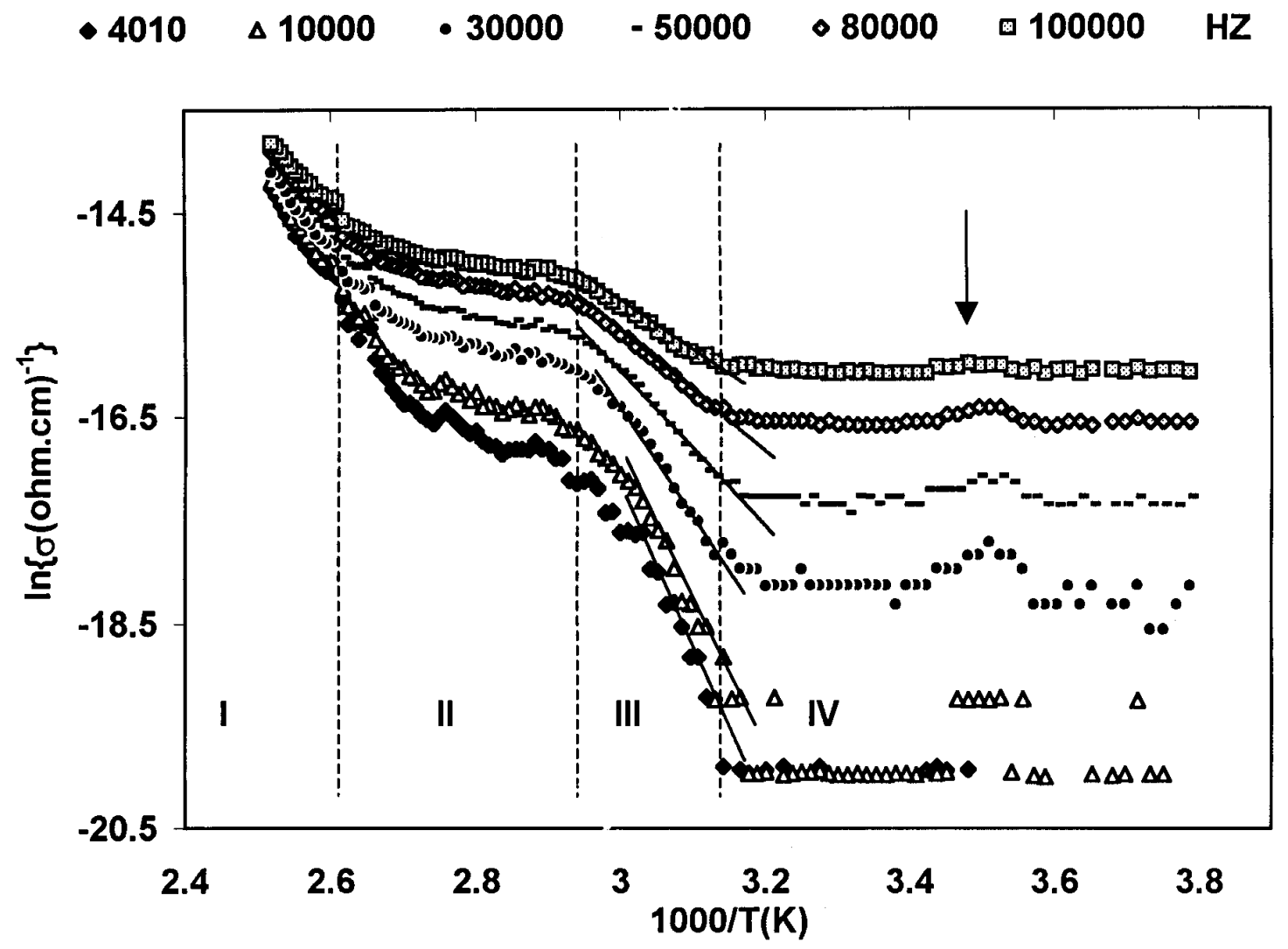

Fig. 5. The Arrhenius plot of the conductivity.

Table 5. Activation energies for the different phases of $\left[\left(\mathrm{CH}_{2}\right)_{9}\left(\mathrm{NH}_{3}\right)_{2}\right] \mathrm{CuCl}_{4}$.

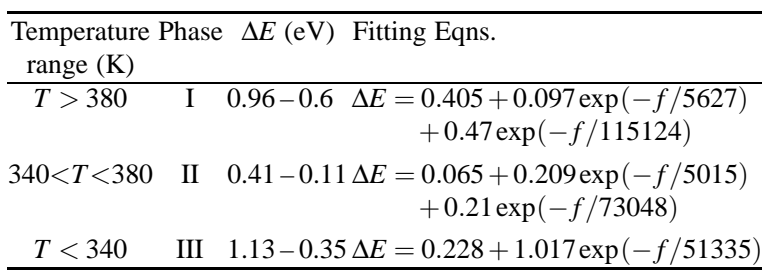

found. Calculations of the activation energies $(\Delta E)$ according to the Arrhenius relation were carried out. The values of $\Delta E$ for the different phases are listed in Table 5 . The values for the phases I and II lie in the range of ionic conduction. For phase II the low activation energy is in the range usually found for protonic conduction. The dependence of the activation energy in the different regions was fitted to the equations listed in Table 5, and the results of the fit are shown in Figure 6 . The results of the fits indicate a first order exponential decay of the activation energies with frequency for phase I and a second order exponential decay for phases II and III as seen in Table 5.

\section{Frequency Dependence}

The dispersive behavior of the conductivity is generally expressed as [23]

$$
\begin{aligned}
& \left.\sigma_{\mathrm{T}} \omega\right)=\left(\sigma_{d c}+\sigma_{\mathrm{ac}},\right. \\
& \sigma_{\mathrm{ac}}=A \omega^{\mathrm{s}},
\end{aligned}
$$

where $\sigma_{\mathrm{dc}}$ and $\sigma_{\mathrm{ac}}$ are the dc and ac conductivity, respectively, the pre-exponential factor $A$ is a temperature dependent constant and the exponent $s$ has usually values between 0 and 1 [23]. Plots of $\ln \sigma_{\mathrm{ac}}$ vs. $\ln \omega$ are characterized by three regions, i) an almost temperature independent plateau region at the lowest frequency $f$ in which $\sigma=c f^{0}$, ii) the Jonscher regime, where $\sigma=c^{\prime} f^{\mathrm{s} 1},(0<\mathrm{s} 1<1)$, iii) a region of high frequency dispersion, where $\sigma=c^{\prime \prime} f^{\mathrm{s} 2},(1<\mathrm{s} 2<2)$. $c, c^{\prime}$ and $c^{\prime \prime}$ are constants, and $f$ is the frequency. Figure 7.a shows the frequency dependence of the conductivity 

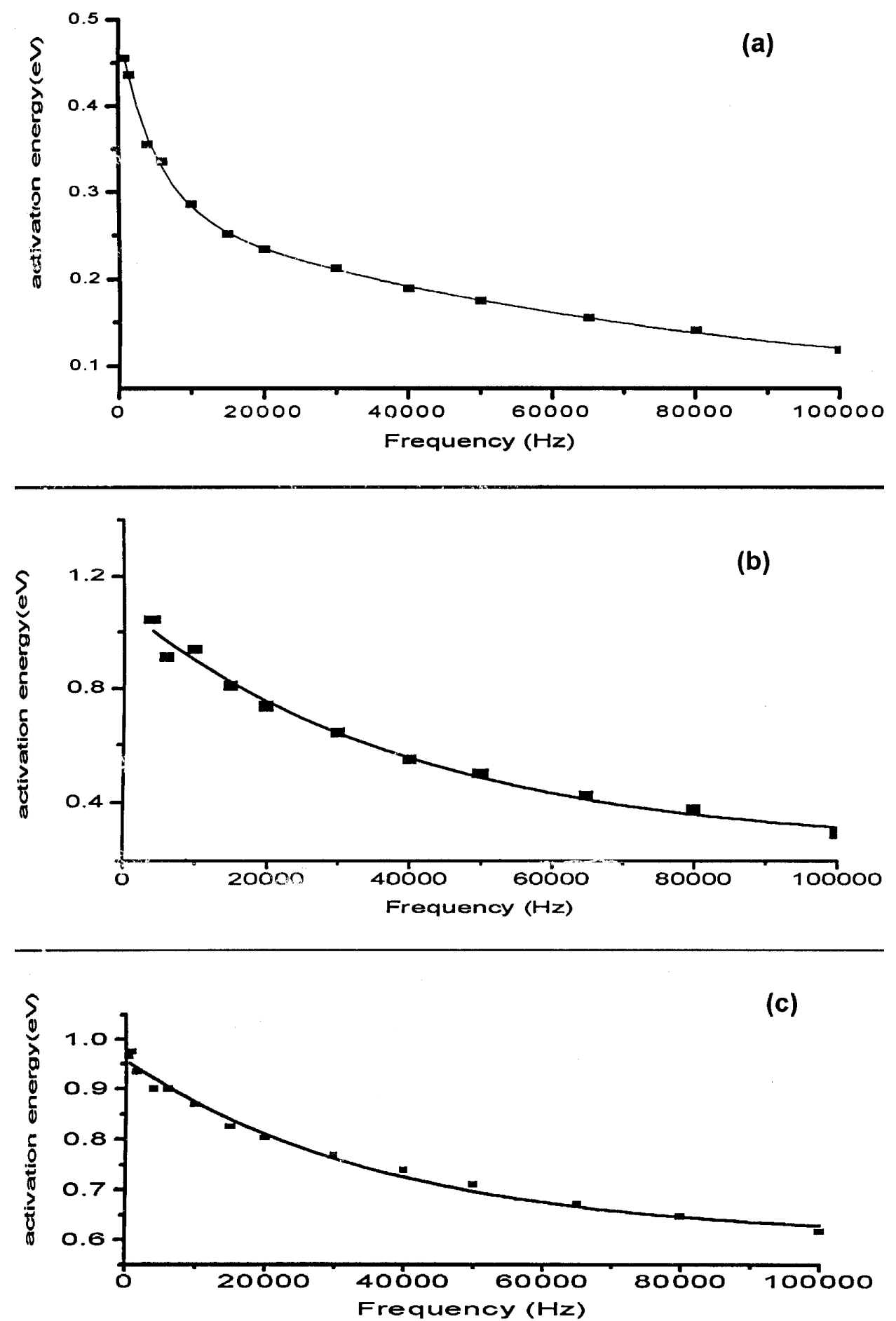

Fig. 6. Variation of the activation energy $\Delta E(\mathrm{eV})$ with frequency. Dots are the data points; lines are the fit results to the equations, in Table 6. (a) and (c): $\mathrm{M}=\mathrm{Cu}$, (b): $\mathrm{M}=\mathrm{Cd}$. 

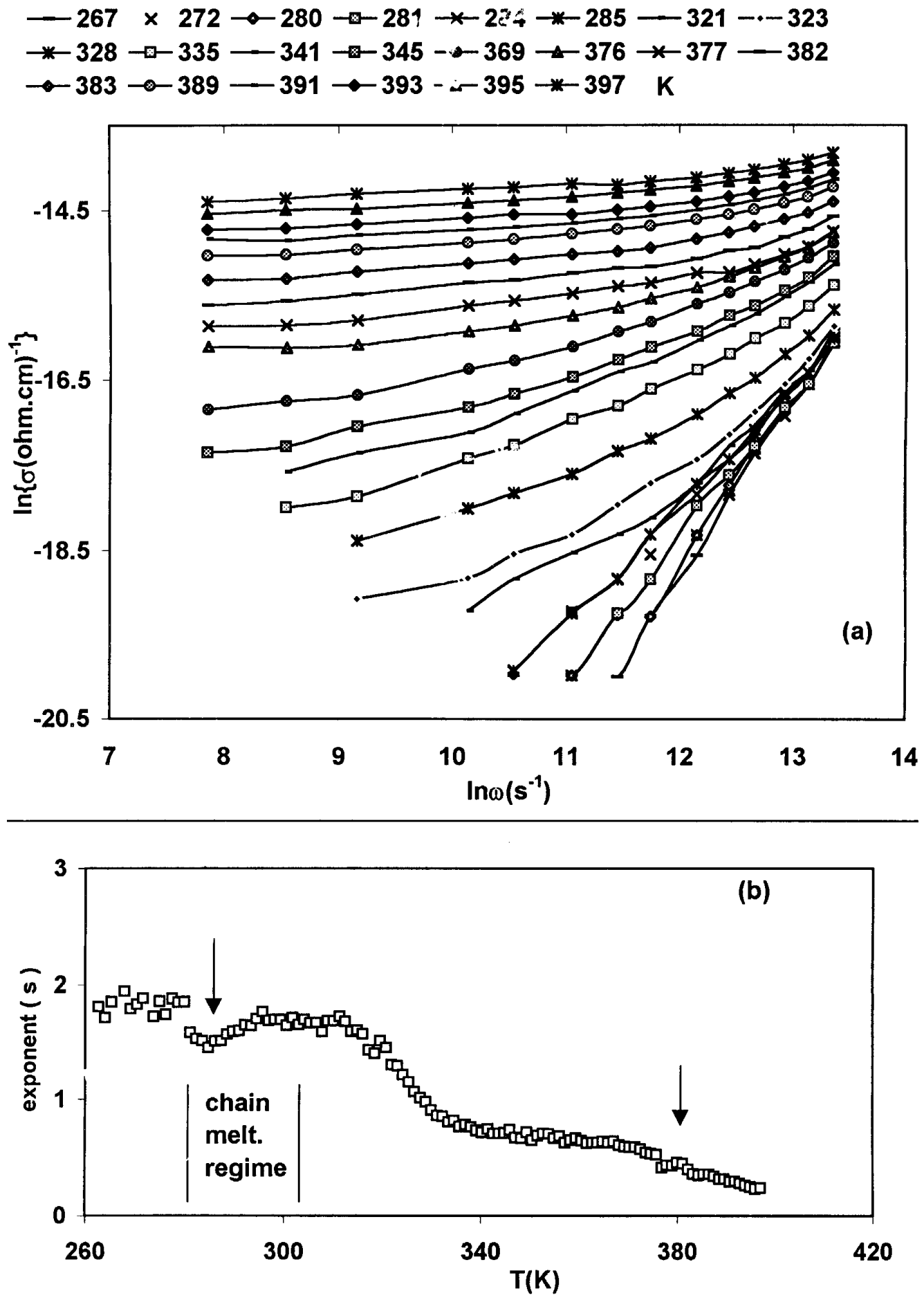

Fig. 7. (a) $\omega=$ frequency, $\sigma_{\mathrm{ai}}=\mathrm{AC}$ conductivity. $\ln \left(\sigma_{\mathrm{ac}}\right)$ as function of $\ln (\omega)$ at different temperatures. (b) The universal exponent (s) as function of temperature (see text). 
at different temperatures as $\ln (\sigma)$ vs. $\ln (\omega)$. At low temperatures, below $320 \mathrm{~K}$, and for frequencies $f<$ $600 \mathrm{~Hz}$, the data were scattered, hence omitted from the plot.

The best fit for the data, collected while heating up, by subtracting $\sigma_{\mathrm{dc}}$, is obtained using a power law according to (3). The values obtained at low temperatures and high frequencies were found to be in the range $1<\mathrm{s} 1<2$ in agreement with a well-localized hopping and/or reorientational motion $[6,14,26]$. Due to the values of $s$ in the range 1.0-0.5, and their temperature dependence in the range $346 \mathrm{~K}<T<380 \mathrm{~K}$, phase II can most probably be ascribed to proton hopping. For temperatures $T>380 \mathrm{~K}, s$ is very small $(0.4-0.2)$, which is usually found in band type conduction [27].

It is to be noted that anomalous changes in the universal exponent $s$ are found around $288 \mathrm{~K}, 346 \mathrm{~K}$, and $383 \mathrm{~K}$, which reflects quite clearly the phase transformations. Thus the universal exponent is not only directly related to the conduction mechanism, but it is also very sensitive to structural transformation.

Previous work on the isomorphous materials $\left[\left(\mathrm{CH}_{2}\right)_{10}\left(\mathrm{NH}_{3}\right)_{2}\right] \mathrm{CdCl}_{4}$ and $\left[\left(\mathrm{CH}_{2}\right)_{12}\left(\mathrm{NH}_{3}\right)_{2}\right] \mathrm{CuCl}_{4}$, henceforth named $\mathrm{CdC10}$ and $\mathrm{CuC12}$, respectively, shows that each material undergoes three phase transitions at $360 \mathrm{~K}, 413 \mathrm{~K}$ and $430 \mathrm{~K}$ and $358 \mathrm{~K}, 412 \mathrm{~K}$ and $433 \mathrm{~K}$, respectively $[14,15]$. The minor differences in the transition temperatures means that the role played by the transition metal ion is small, and that increasing the length of the chain by a small value-addition of two carbon atoms does not affect the transition temperature. On the other hand, for $\mathrm{CuC} 9$ the corresponding transitions occur at a much lower temperatures. The major peak of the chain rotational transition occurs at $T \backsim 346 \mathrm{~K}$, which is by $\sim 15 \mathrm{~K}$ lower than the corresponding transition of the corresponding $\mathrm{CuC} 12$ $(T=358 \mathrm{~K})$. This is also true for the order disorder transition at $383 \mathrm{~K}$, which is by about $30 \mathrm{~K}$ lower than that found for CuC12 $(T=412)$ [15]. This is most likely due to the difference in symmetry found for samples with an even and odd number of carbon atoms. We have also found that the obtained activation energies for hopping in case of $\mathrm{CuC} 9$ are different from those for the other two materials with even number of carbon atoms previously studied, except for phase I, band type conduction, where the activation energy is the same, see Table 6. Also the universal exponent $s$ and its temperature dependence for materials with even
Table 6. Activation energies for different phases of $\left[\left(\mathrm{CH}_{2}\right)_{n}\right.$ $\left.\left(\mathrm{NH}_{3}\right)_{2}\right] \mathrm{MCl}_{4}, n=9$ and $12: \mathrm{M}=\mathrm{Cu}, n=10: \mathrm{M}=\mathrm{Cd}$.

\begin{tabular}{clcc}
\hline Temperature range $(\mathrm{K})$ & \multicolumn{1}{c}{ CuC9 } & $\begin{array}{c}\Delta E(\mathrm{eV}) \\
\mathrm{CdC} 10\end{array}$ & $\mathrm{CuC} 12$ \\
\hline$T>380$ & $1.13-0.35$ & $\ldots$ & $0.8-0.007$ \\
$350<T<380$ & $0.41-0.11$ & 0.89 & $0.6-0.03$ \\
$T<340$ & $0.9-0.6$ & 0.95 & $\ldots$ \\
\hline
\end{tabular}

and odd number of carbon atoms in phase I is nearly the same. This indicates that the mechanism of conduction with nearly the same band gap energy is the same, irrespective of the number of carbon atoms. It is likely that the materials will have the same crystalline structure in this high temperature range. For $T<346 \mathrm{~K}$, the average value of $\Delta E$ is higher for the $\mathrm{C} 9 \mathrm{Cu}$ than for the $\mathrm{CuC12}$. In this temperature range it is expected that the even numbered carbon atom materials $(\mathrm{CdC} 10$ and $\mathrm{CuC12}$ ) have monoclinic unit cells, while the odd numbered carbon atom $\mathrm{CuC} 9$ has an orthorhombic unit cell. This would account for the difference in activation energy. It is also to be pointed out that for the $\mathrm{CuC} 9$ an activation energy in the range $0.41-0.11 \mathrm{eV}$ is found, which most likely can be associated with proton type conduction. Such activation energies were not observed for $\mathrm{CuC} 12$ and $\mathrm{CdC} 10$.

\section{Conclusion}

Thermal, magnetic and electric measurements on CuC9 showed one minor and four major phase transitions. The two transitions below room temperature are ascribed to structural phase changes. Near ambient temperature, the chain melting transition is found accompany a sudden drop in permittivity. A large increase in the permittivity is observed near the transition at $346 \mathrm{~K}$. This is due to fluctuation of dipole moments as a result of conformational motion of the alkylene chains The highest temperature transition, at $383 \mathrm{~K}$, is ascribed to order-disorder transition, where an anomalous change in the permittivity due to rearrangement of dipole moments is found. The magnetic susceptibility at low temperatures shows changes in the magnetic moment around the transitions at $T_{3}$ and $T_{4}$. The magnetic moment in that temperature range indicates distorted $\mathrm{CuCl}_{4}$ octahedra. A band type conduction is found for phase I, while proton type conduction is likely to predominate in phase II. In phase III the conductivity has been found to take place via ionic hopping as well as localized or reorientational hopping. 
[1] R. Kind, S. Plesko, and J. Roos, Phys. Stat. Sol. 47a, 233 (1978).

[2] J. Tichy, R. Benes, W. Halg, and H. Arend, Acta. Cryst. B34, 2970 (1978).

[3] C. Socfas, M. Arriendiaga, M. Telo, J. Fernandez, and P. Gili, Phys. Stat. Sol. 57a, 405 (1980).

[4] R. Kind, S. Plesko, P. Gunter, J. Roos, and J. Fousek, Phys. Rev. B23, 5301 (1981).

[5] L. Battaglia, R. Corradi, G. Pelosi, M. Cramarossa, T. Manferdini, G. Pellaceni, A. Motori, R. Saccani, F. Sandrolini, and M. Brigatti, Chem. Matter 4, 813 (1992).

[6] M. F. Mostafa and R. D. Willett, Phys. Rev. B4, 2213 (1971).

[7] R. Jakuba, G. Bator, P. Ciapala, J. Zaleski, J. Baran, and J. Lefebvre, J. Phys. Condens. Matter 7, 5335 (1995).

[8] L. J. De Jongh and A. R. Miedema, Adv. Phys. 23, 1 (1974).

[9] M. F. Mostafa, M. A. Semary, and M. M. Abdel-Kader, Physica, 112B, 197 (1982).

[10] C. Courseille, N. Chanh, Th. Maris, A. Daoud, Y. Abed, and M. Laguerre, Phys. Stat. Sol. 143a, 203 (1994).

[11] M. F. Mostafa, A. S. Atallah, and R. Emrick, J. Appl. Phys. 81, 4134 (1997).

[12] M. F. Mostafa and S. Montasser, Z. Naturforsch. 55a, 945 (2000).
[13] A. A. Youssef, Z. Naturforsch. 57a, 263 (2002).

[14] M. F. Mostafa and A. A. Youssef, Z. Naturforsch. 56a, 568 (2001).

[15] M.F. Mostafa and S. A. El-Hakim, Phase Transitions 57, 1 - 13 (2002).

[16] G. Chapuis, H. Arend, and R. Kind, Phys. Stat. Sol. 31a, 449 (1975).

[17] S. Karup and R. J. Burg, Sol. Stat. Chem. 26, 59 (1978).

[18] R.E. Jacobs, B.S. Hudson, and H.C. Anderson, Biochem. 16, 4349 (1977).

[19] G. Needham, R. D. Willett, and H. Franzen, J. Phys. Chem. 88, 674 (1984).

[20] K. Knorr, I. R. Jahn, and G. Heger, Sol. Stat. Comm. 15, 231 (1974).

[21] H. Kasano, N. Koshiji, and H. Mashiyama, J. Phys. Soc. (Japan) 61, 348 (1992).

[22] P. B. Macedo, C. T. Moynihan, and R. Bose, Physics and Chemistry of Glasses 13, 171 (1972).

[23] A. K. Jonscher. Dielectric Relaxation in Solids. Chelsea Dielectric Press, London 1983, p. 344.

[24] A. R. Long, Adv. Phys. 31, 553 (1982).

[25] S. R. Elliott, Adv. Phys. 36, 135 (1987).

[26] M. F. Mostafa, M. M. AbdelKader, A. S. Atallah, and M. ElNimer, Phys. Stat. Sol. 135a, 549 (1993).

[27] M. F. Mostafa, A. A. A. Youssef, and S. A. El-Hakim, Phase Transitions (in press). 